\title{
ChemComm
}

\section{Rhodium-catalyzed intramolecular alkynylsilylation of alkynes $\dagger$}

Cite this: Chem. Commun., 2015, 51, 11378

Received 20th May 2015,

Accepted 4th June 2015

DOI: $10.1039 / c 5 c c 04172 d$

www.rsc.org/chemcomm

Rhodium-catalyzed intramolecular alkynylsilylation of alkynes is described. The reaction proceeds through syn-insertion by a cationic rhodium/triarylphosphine catalyst, representing the first alkynylsilylation of alkynes via the cleavage of a C(sp)-Si bond by transition-metal catalysis. A highly enantioselective variant is also described for the creation of a silicon stereogenic center.

Stereoselective insertion of alkynes into carbon-silicon bonds represents a powerful and efficient approach for the synthesis of highly substituted alkenylsilanes. Most of the reported examples employ either strained organosilicon substrates ${ }^{1}$ or (Lewis) acid catalysts/additives ${ }^{2}$ to promote the reaction to achieve alkyl- ${ }^{1 a-f}$ allyl-,${ }^{19-i, 2 b-e, 3}$ alkenyl- ${ }^{1 g-j, 2 f-i, 4}$ aryl- ${ }^{1 b, k, 2 h, i}$ and propargyl/allenylsilylation ${ }^{2 j}$ of alkynes. More reactive acylsilanes $^{5}$ and trimethylsilylcyanide ${ }^{6}$ are also known to undergo insertion of alkynes to give 2-acyl- and 2-cyanoalkenylsilanes, respectively. In contrast, virtually no progress has been made for alkyne insertion into alkynylsilanes. In fact, there has been only one report where they described a formal insertion reaction through conjugate addition of 2-silylynamides to acetylenedicarboxylates followed by silyl migration. ${ }^{7,8}$ In this communication, we describe the development of rhodium-catalyzed intramolecular alkynylsilylation of alkynes through the cleavage of a C(sp)-Si bond under mild conditions, including a highly enantioselective variant for the construction of a silicon stereogenic center. ${ }^{9}$

During the course of our study directed toward the development of synthetic methods for various silicon-bridged $\pi$-conjugated compounds,$^{10}$ we attempted to synthesize benzonaphthosiline 2a from silicon-containing diyne $\mathbf{1 a}$ and 1,4-dimethoxy-2-butyne through a rhodium-catalyzed $[2+2+2]$ cycloaddition reaction. ${ }^{11}$ As shown in eqn (1), under the conditions of using a cationic

Department of Chemistry and Biotechnology, Graduate School of Engineering,

The University of Tokyo, 7-3-1 Hongo, Bunkyo-ku, Tokyo 113-8656, Japan.

E-mail:shintani@chembio.t.u-tokyo.ac.jp,nozaki@chembio.t.u-tokyo.ac.jp;

Fax: +81-3-5841-7263; Tel: +81-3-5841-7261

$\dagger$ Electronic supplementary information (ESI) available: Detailed experimental procedures. CCDC 1401151. For ESI and crystallographic data in CIF or other electronic format see DOI: 10.1039/c5cc04172d
$\mathrm{Rh} / 2 \mathrm{PPh}_{3}$ catalyst generated in situ, only $9 \%$ yield of the desired product 2a was obtained and the major product turned out to be an intramolecular alkynylsilylation product $3 \mathrm{a}$ in $20 \%$ yield. On the basis of this unexpected result, we decided to focus on the improvement of this alkynylsilylation reaction by rhodium catalysis. To our surprise, however, simple removal of 1,4-dimethoxy2-butyne from the reaction in eqn (1) did not provide 3a at all (eqn (2)). We hypothesized that this seemingly inconsistent result might indicate that the coordination of 1,4-dimethoxy-2-butyne to rhodium had a beneficial effect on promoting the alkynylsilylation of 1a. We then tried to search for an innocent replacement and found that the use of $\mathrm{MeCN}$ as an additive gave product 3a in $51 \%$ yield, and a higher yield of $82 \%$ was achieved by changing the ratio of $\mathrm{Rh} / \mathrm{PPh}_{3}$ from $1 / 2$ to $1 / 1{ }^{12}$
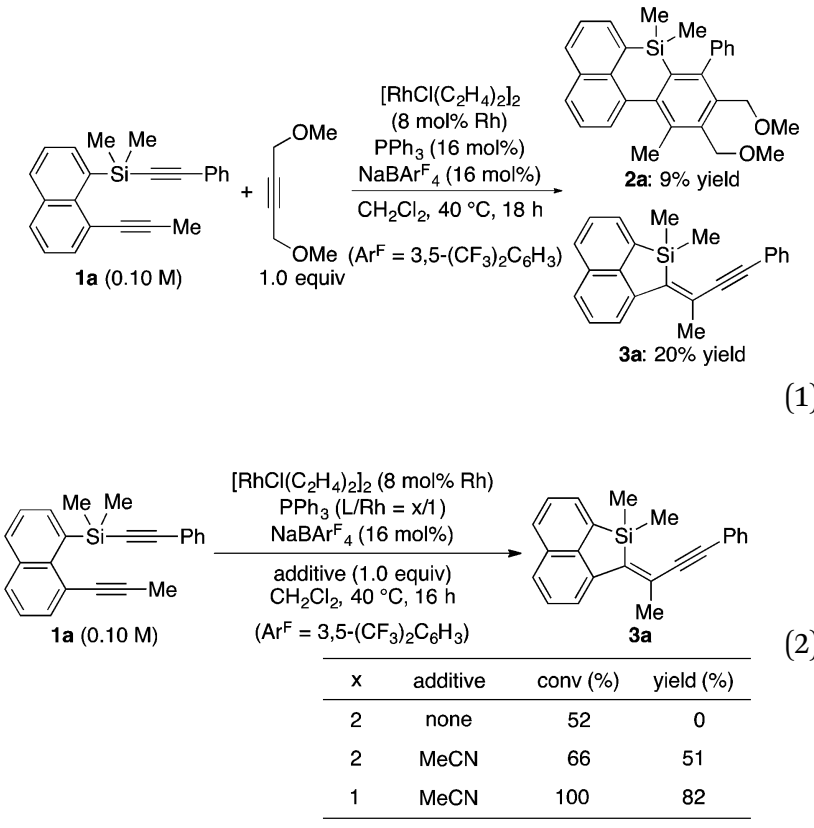

Under these conditions, several different alkynyl groups on the silicon atom of $\mathbf{1}$ are tolerated in the present intramolecular alkynylsilylation reaction to give the corresponding 3 in high yields, 
Table 1 Rhodium-catalyzed alkynylsilylation: scope ${ }^{a}$

\begin{tabular}{llll}
\hline Entry & Substrate & Product & Yield $^{b}(\%)$ \\
\hline
\end{tabular}
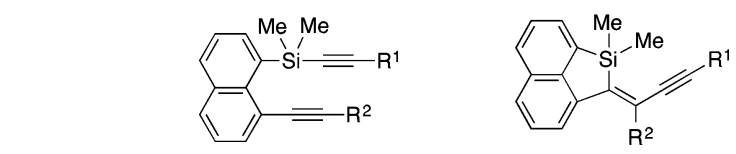

1
$2^{c}$
$3^{e}$
$4^{f}$
$5^{g}$
$6^{c, h}$

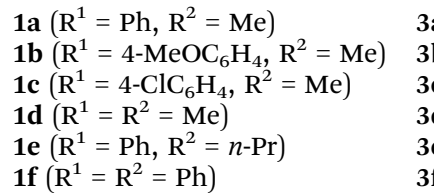
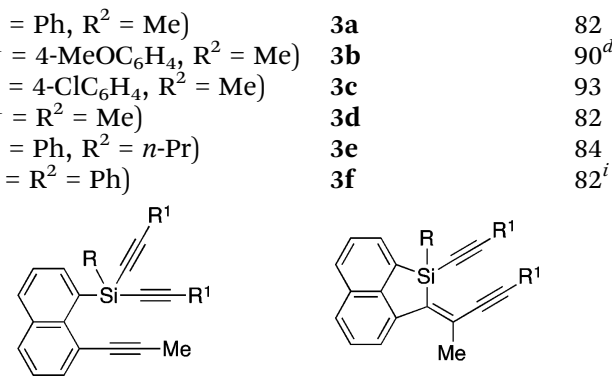

$\begin{array}{ll}7^{g} & \mathbf{1 g}\left(\mathrm{R}=\mathrm{Cy}, \mathrm{R}^{1}=\mathrm{Ph}\right) \\ 8^{c, e} & \mathbf{1 h}\left(\mathrm{R}=\mathrm{Cy}, \mathrm{R}^{1}=\mathrm{Me}\right) \\ 9^{c, h} & \mathbf{1 i}\left(\mathrm{R}=\mathrm{R}^{1}=\mathrm{Me}\right)\end{array}$

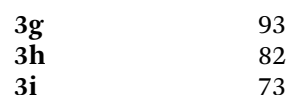

${ }^{a}$ Conditions: $\left[\mathrm{RhCl}\left(\mathrm{C}_{2} \mathrm{H}_{4}\right)_{2}\right]_{2}(8 \mathrm{~mol} \% \mathrm{Rh}), \mathrm{PPh}_{3}(8 \mathrm{~mol} \%), \mathrm{NaBAr}_{4}{ }^{\mathrm{F}}$ (16 mol\%), MeCN (1.0 equiv.), $\mathrm{CH}_{2} \mathrm{Cl}_{2}(0.10 \mathrm{M}), 40{ }^{\circ} \mathrm{C}, 16 \mathrm{~h} .{ }^{b}$ Isolated yield ( $Z$-isomer was obtained exclusively unless otherwise noted). ${ }^{c}$ The reaction was conducted at $0.05 \mathrm{M}$ substrate concentration. ${ }^{d} Z / E=98 / 2$. ${ }^{e}$ The reaction time was $1 \mathrm{~h} .{ }^{f}$ The reaction was conducted at $80{ }^{\circ} \mathrm{C}$ in toluene. ${ }^{g}$ The reaction time was $2 \mathrm{~h} .{ }^{h}$ The reaction was conducted with $\mathrm{P}\left(4-\mathrm{MeOC}_{6} \mathrm{H}_{4}\right)_{3}$ instead of $\mathrm{PPh}_{3} \cdot{ }^{i} Z / E=94 / 6$.

although an elevated temperature is necessary for the reaction of 1-propynyl substituted substrate 1d (Table 1, entries 1-4). The structure of $\mathbf{3 b}$ was confirmed by X-ray crystallographic analysis, establishing the syn-insertion of an alkyne into the alkynylsilane in the present catalysis. ${ }^{13}$ With respect to the alkynyl substituent at the 8-position of the naphthalene tether, in addition to alkyl groups such as 1a and 1e, aryl groups such as $\mathbf{1}$ can also be effectively employed by changing the ligand from $\mathrm{PPh}_{3}$ to $\mathrm{P}\left(4-\mathrm{MeOC}_{6} \mathrm{H}_{4}\right)_{3}$ (entries 1, 5 and 6). Substrates 1g-1i having an alkylbis(alkynyl)silyl group at the 1-position are also suitable for the present alkynylsilylation to give $3 \mathbf{g}-3 \mathbf{i}$ in $73-93 \%$ yield (entries 7-9). Furthermore, the reaction is applicable to substrates containing some other tethers as well. As shown in eqn (3) and (4), 1,2-bis(dimethyl(phenylethynyl)silyl)benzene (1j) and 1,8-bis(dimethyl(phenylethynyl)silyl)naphthalene (1k) similarly undergo intramolecular alkynylsilylation to give products $\mathbf{3} \mathbf{j}$ and $\mathbf{3 k}$ in high yields. The reaction also proceeds smoothly with substrate $\mathbf{4}$ having two alkynylsilane moieties through the two-fold alkynylsilylation
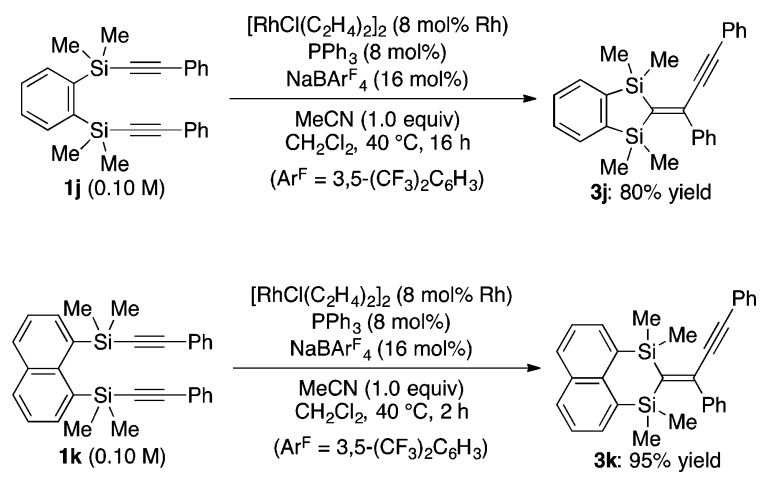

process, giving a highly conjugated product 5 in $78 \%$ yield (eqn (5)). ${ }^{14}$
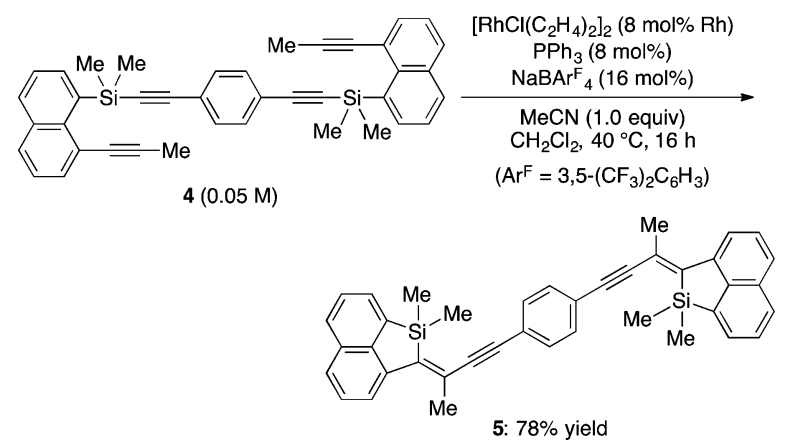

A proposed catalytic cycle for the reaction of $\mathbf{1 a}$ to $\mathbf{3 a}$ is illustrated in scheme 1. Coordination of $\mathbf{1 a}$ to cationic rhodium(I) in the form of $\mathbf{A}$ facilitates the oxidative addition of a $\mathrm{C}(\mathrm{sp})-\mathrm{Si}$ bond to give intermediate B. Successive intramolecular insertion of alkyne into a $\mathrm{Si}-\mathrm{Rh}$ bond provides alkenyl(alkynyl)rhodium(III) C, reductive elimination of which leads to the formation of product 3a along with regeneration of the cationic rhodium(I) species. Although the role of MeCN is not yet completely understood, it probably stabilizes coordinatively unsaturated rhodium intermediates during the catalytic cycle. To gain some insights into the present catalysis, we conducted the following control experiments as shown in eqn (6) and (7). By changing the electronic properties of the triarylphosphine ligand in the reaction of 1a, we determined that the reaction proceeds faster by using more electron-rich phosphine ligands (eqn (6)). We also found that electron-deficient alkynylsilanes tend to react faster by changing the para-substituent of the arylethynyl group on the silicon of 1 (eqn (7)). Both these results are consistent with the assumption

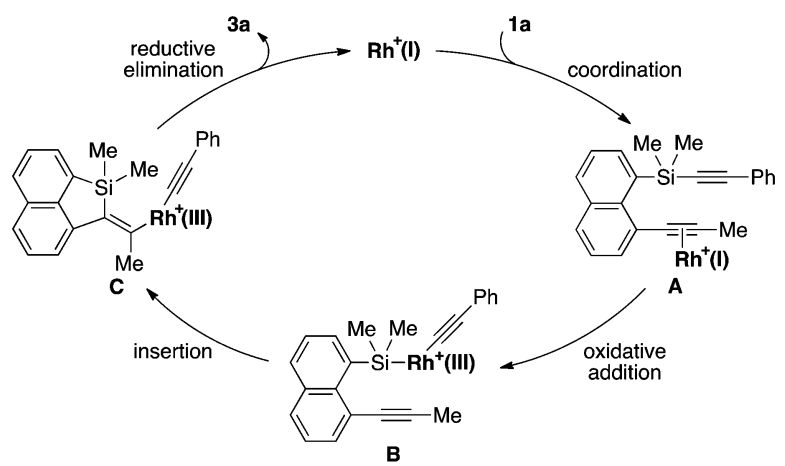

Scheme 1 Proposed catalytic cycle for the rhodium-catalyzed intramolecular alkynylsilylation of 1 a.

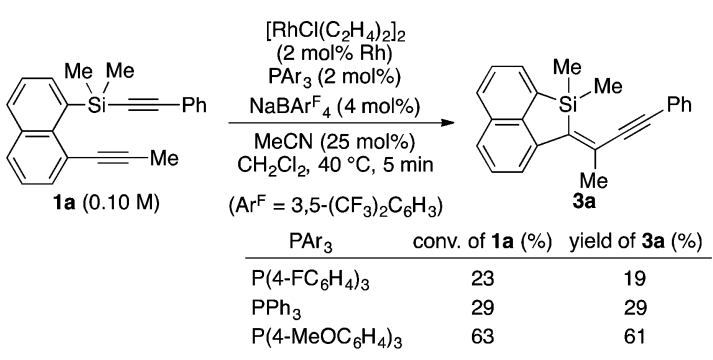



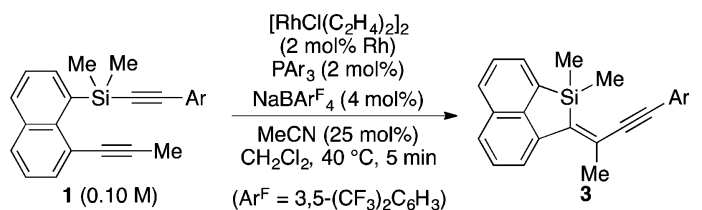

Table 2 Rhodium-catalyzed asymmetric alkynylsilylation

\begin{tabular}{|c|c|c|c|c|c|}
\hline & $\int_{\mathrm{Si}=\mathrm{Me}}^{\mathrm{Ph}}$ & $\begin{array}{r}{\left[\mathrm{RhCl}\left(\mathrm{C}_{2} \mathrm{H}_{4}\right)_{2}\right.} \\
\text { ligand } \\
\mathrm{NaBAr}_{4} \\
\text { additive } \\
\mathrm{CH}_{2} \mathrm{C}\end{array}$ & $\begin{array}{l}10 \text { mol\% Rh) } \\
\text { mol\%) } \\
\text { O mol\%) } \\
\text { equiv) } \\
40^{\circ} \mathrm{C}\end{array}$ & $\begin{array}{c}\mathrm{Me} \\
\mathbf{3 g}\end{array}$ & \\
\hline Entry & Ligand & & Additive & Yield $^{a}(\%)$ & $\mathrm{ee}^{b}(\%)$ \\
\hline 1 & $(R)$-MeO-mo & & $\mathrm{MeCN}$ & 77 & 0 \\
\hline 2 & (R)-MeO-mo & & None & 23 & $83(-)$ \\
\hline 3 & $(S)$-Ph-phox & & None & 74 & $69(+)$ \\
\hline 4 & (R)-iPr-phox & & None & 27 & $42(-)$ \\
\hline 5 & $(S, S, S)$-Phos & horamidite & None & 60 & $36(+)$ \\
\hline 6 & $(R, S, S)$-Phos & phoramidite & None & 53 & $92(+)$ \\
\hline $7^{c}$ & $(R, S, S)$-Phos & ohoramidite & None & $62(59)^{d}$ & $94(+)$ \\
\hline
\end{tabular}

${ }^{a}$ Determined by ${ }^{1} \mathrm{H}$ NMR against an internal standard. ${ }^{b}$ Determined by chiral HPLC on a Chiralcel OD-H column with hexane/2-propanol = $98 / 2 .{ }^{c}$ The reaction was conducted at $0.03 \mathrm{M}$ substrate concentration. ${ }^{d}$ Isolated yield in parentheses.

that the oxidative addition is the turnover-limiting step in the catalytic cycle, although further evidence is necessary to fully establish the catalytic cycle.

Finally, we have also begun to develop an asymmetric variant of this process. ${ }^{15}$ On the basis of the conditions for the nonasymmetric reactions, we conducted a reaction of prochiral $1 \mathrm{~g}$ by employing $(R)$-MeO-mop, ${ }^{16}$ a chiral monophosphine ligand, in the presence of 1.0 equiv. of MeCN. Under these conditions, $77 \%$ yield of $\mathbf{3 g}$ was obtained, but no asymmetric induction was observed at the silicon stereocenter (Table 2, entry 1). In comparison, $83 \%$ ee was achieved with the same ligand in the absence of $\mathrm{MeCN}$, but the yield of $\mathbf{3 g}$ became significantly lower (entry 2). To accommodate the nitrogen coordination to the structure of a chiral ligand, we examined (S)-Ph-phox, ${ }^{17}$ a P,N-bidentate ligand, and found that $3 \mathrm{~g}$ was produced in $74 \%$ yield in the absence of MeCN with an appreciable ee of $69 \%$ (entry 3). Unfortunately, however, further improvement was unsuccessful by using other phosphinooxazoline ligands such as $(R)$-iPr-phox ${ }^{17}$ (entry 4). As a different structural motif for the chiral ligand, we also employed phosphoramidite ligands. ${ }^{18}$ For example, the use of $(S, S, S)$-phosphoramidite having a 2,5-diphenylpyrrolidine moiety ${ }^{19}$ gave $\mathbf{3 g}$ in $60 \%$ yield with $36 \%$ ee in the absence of MeCN (entry 5). We subsequently found that significantly higher enantioselectivity (92\% ee) could be achieved by changing the ligand to its diastereomer $((R, S, S) \text {-phosphoramidite })^{19 a, 20}$ with a moderate yield of $53 \%$ (entry 6 ). Both the yield and the ee were slightly improved further by lowering the initial substrate concentration from $0.10 \mathrm{M}$ to $0.03 \mathrm{M}$ to give $62 \%$ yield (59\% isolated yield) of $3 \mathrm{~g}$ with $94 \%$ ee (entry 7 ).

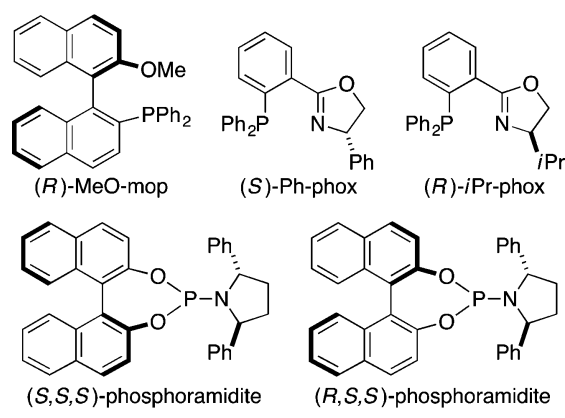

In summary, we have developed rhodium-catalyzed intramolecular alkynylsilylation of alkynes under mild conditions. The reaction proceeds through syn-insertion in the presence of a cationic rhodium/triarylphosphine catalyst with MeCN as an additive. Although applicable substrates are currently still limited, this represents the first alkynylsilylation of alkynes via the cleavage of a C(sp)-Si bond by transition-metal catalysis. We have also described our preliminary investigation of its asymmetric variant, creating a silicon stereogenic center with high enantioselectivity. Future studies will be directed toward the development of a more general catalyst system to expand the scope of alkynylsilylation of alkynes and related reactions.

Support has been provided in part by Challenging Exploratory Research, the Ministry of Education, Culture, Sports, Science and Technology, Japan. We thank Prof. Takuzo Aida and Dr Yoshimitsu Itoh at The University of Tokyo for the measurement of fluorescence spectra.

\section{Notes and references}

1 (a) H. Sakurai and T. Imai, Chem. Lett., 1975, 891; (b) Y. Takeyama, K. Nozaki, K. Matsumoto, K. Oshima and K. Utimoto, Bull. Chem. Soc. Jpn., 1991, 64, 1461; (c) Z. Nevárez and K. A. Woerpel, Org. Lett., 2007, 9, 3773; (d) R. Shintani, K. Moriya and T. Hayashi, J. Am. Chem. Soc., 2011, 133, 16440; (e) R. Shintani, K. Moriya and T. Hayashi, Org. Lett., 2012, 14, 2902; $(f)$ J. Liu, Q. Zhang, P. Li, Z. Qu, S. Sun, Y. Ma, D. Su, Y. Zong and J. Zhang, Eur. J. Inorg. Chem., 2014, 3435; $(g)$ H. Saso and W. Ando, Chem. Lett., 1988, 1567; $(h)$ H. Saso, W. Ando and K. Ueno, Tetrahedron, 1989, 45, 1929; (i) K. M. Buchner and K. A. Woerpel, Organometallics, 2010, 29, 1661; ( $j$ ) J. Liu, X. Sun, M. Miyazaki, L. Liu, C. Wang and Z. Xi, J. Org. Chem., 2007, 72, 3137; (k) N. Agenet, J.-H. Mirebeau, M. Petit, R. Thouvenot, V. Gandon, M. Malacria and C. Aubert, Organometallics, 2007, 26, 819.

2 For a review: (a) K. Motokura and T. Baba, Green Chem., 2012, 14, 565; For examples: $(b)$ N. Asao, E. Yoshikawa and Y. Yamamoto, J. Org. Chem., 1996, 61, 4874; (c) E. Yoshikawa, V. Gevorgyan, N. Asao and Y. Yamamoto, J. Am. Chem. Soc., 1997, 119, 6781; (d) T. Matsuda, S. Kadowaki, Y. Yamaguchi and M. Murakami, Chem. Commun., 2008, 2744; (e) K. Motokura, S. Matsunaga, A. Miyaji, T. Yashima and T. Baba, Tetrahedron Lett., 2011, 52, 6687; $(f)$ N. Asao, T. Shimada and Y. Yamamoto, J. Am. Chem. Soc., 1999, 121, 3797; (g) N. Asao, K. Nabatame and Y. Yamamoto, Chem. Lett., 2001, 982; (h) N. Asao, T. Shimada, T. Shimada and Y. Yamamoto, J. Am. Chem. Soc., 2001, 123, 10899; (i) T. Matsuda, Y. Yamaguchi, M. Shigeno, S. Sato and M. Murakami, Chem. Commun., 2011, 47, 8697; (j) E. Yoshikawa, M. Kasahara, N. Asao and Y. Yamamoto, Tetrahedron Lett., 2000, 41, 4499.

3 For a radical process: K. Miura, H. Saito, T. Nakagawa, T. Hondo, J. Tateiwa, M. Sonoda and A. Hosomi, J. Org. Chem., 1998, 63, 5740. 
4 For a ruthenium-catalyzed intramolecular process: S. Liu, J. Zhao, L. Kaminsky, R. J. Wilson, M. Marino and D. A. Clark, Org. Lett., 2014, 16, 4456.

5 (a) H.-J. Zhang, P. Becker, H. Huang, R. Pirwerdjan, F.-F. Pan and C. Bolm, Adv. Synth. Catal., 2012, 354, 2157; (b) P. Becker, D. L. Priebbenow, H.-J. Zhang, R. Pirwerdjan and C. Bolm, J. Org. Chem., 2014, 79, 814.

6 N. Chatani, T. Takeyasu, N. Horiuchi and T. Hanafusa,J. Org. Chem., 1988, 53, 3539.

7 H. Gerhard, J. Chem. Res., Synop., 1978, 104.

8 For alkynylsilylation of alkynes by a three-component-coupling reaction: N. Chatani, N. Amishiro and S. Murai, J. Am. Chem. Soc., 1991, 113, 7778.

9 For recent reviews on the synthesis of enantio-enriched siliconstereogenic organosilanes: (a) M. Oestreich, Synlett, 2007, 1629; (b) A. Weickgenannt, M. Mewald and M. Oestreich, Org. Biomol. Chem., 2010, 8, 1497; (c) L.-W. Xu, L. Li, G.-Q. Lai and J.-X. Jiang, Chem. Soc. Rev., 2011, 40, 1777; (d) L.-W. Xu, Angew. Chem., Int. Ed., 2012, 51, 12932; (e) R. Shintani, Asian J. Org. Chem., 2015, 4, 510.

10 (a) R. Shintani, H. Otomo, K. Ota and T. Hayashi, J. Am. Chem. Soc., 2012, 134, 7305; (b) R. Shintani, E. E. Maciver, F. Tamakuni and T. Hayashi, J. Am. Chem. Soc., 2012, 134, 16955; (c) R. Shintani, C. Takagi, T. Ito, M. Naito and K. Nozaki, Angew. Chem., Int. Ed., 2015, 54, 1616.

11 For recent reviews on the rhodium-catalyzed $[2+2+2]$ cycloaddition reactions, see: (a) K. Tanaka, Chem. - Asian J., 2009, 4, 508; (b) N. Weding and M. Hapke, Chem. Soc. Rev., 2011, 40, 4525; (c) Y. Shibata and K. Tanaka, Synthesis, 2012, 323; (d) D. L. J. Broere and E. Ruijter, Synthesis, 2012, 2639.

12 The use of $8 \mathrm{~mol} \%$ of $\mathrm{NaBAr}_{4}{ }^{\mathrm{F}}$ instead of $16 \mathrm{~mol} \%$ also provided $3 \mathrm{a}$ with similar efficiency.

13 CCDC 1401151. See also the Electronic ESI $\dagger$ for details.

14 See the ESI $\dagger$ for the optical properties of compound 5.
15 For examples of catalytic asymmetric preparation of siliconstereogenic organosilanes, see: $(a)$ R. J. P. Corriu and J. J. E. Moreau, Tetrahedron Lett., 1973, 14, 4469; (b) T. Hayashi, K. Yamamoto and M. Kumada, Tetrahedron Lett., 1974, 15, 331; (c) R. J. P. Corriu and J. J. E. Moreau, J. Organomet. Chem., 1975, 85, 19; (d) R. J. P. Corriu and J. J. E. Moreau, J. Organomet. Chem., 1976, 120, 337; (e) T. Ohta, M. Ito, A. Tsuneto and H. Takaya, J. Chem. Soc., Chem. Commun., 1994, 2525; $(f)$ Y. Yasutomi, H. Suematsu and T. Katsuki, J. Am. Chem. Soc., 2010, 132, 4510; $(g)$ Y. Kurihara, M. Nishikawa, Y. Yamanoi and H. Nishihara, Chem. Commun., 2012, 48, 11564; (h) K. Igawa, D. Yoshihiro, N. Ichikawa, N. Kokan and K. Tomooka, Angew. Chem., Int. Ed., 2012, 51, 12745; (i) ref. $1 d, e$ and 10; See also: $(j)$ K. Tamao, K. Nakamura, H. Ishii, S. Yamaguchi and M. Shiro, J. Am. Chem. Soc., 1996, 118, 12469; (k) D. R. Schmidt, S. J. O'Malley and J. L. Leighton, J. Am. Chem. Soc., 2003, 125, 1190; (l) K. Igawa, J. Takada, T. Shimono and K. Tomooka, J. Am. Chem. Soc., 2008, 130, 16132; $(m)$ M. Onoe, K. Baba, Y. Kim, Y. Kita, M. Tobisu and N. Chatani, J. Am. Chem. Soc., 2012, 134, 19477; (n) X. Lu, L. Li, W. Yang, K. Jiang, K.-F. Yang, Z.-J. Zheng and L.-W. Xu, Eur. J. Org. Chem., 2013, 5814.

16 (a) T. Hayashi, Acc. Chem. Res., 2000, 33, 354; (b) Y. Uozumi, A. Tanahashi, S.-Y. Lee and T. Hayashi, J. Org. Chem., 1993, 58, 1945. 17 (a) P. von Matt and A. Pfaltz, Angew. Chem., Int. Ed. Engl., 1993, 32, 566; (b) G. J. Dawson, C. G. Frost, J. M. Williams and S. J. Coote, Tetrahedron Lett., 1993, 34, 3149.

18 For example of $\mathrm{P}$ - $\left(\mathrm{\eta}^{2}\right.$-arene $)$ chelating coordination of a phosphoramidite ligand to rhodium, see: I. S. Mikhel, H. Rüegger, P. Butti, F. Camponovo, D. Huber and A. Mezzetti, Organometallics, 2008, 27, 2937.

19 (a) Y. H. Choi, J. Y. Choi, H. Y. Yang and Y. H. Kim, Tetrahedron: Asymmetry, 2002, 13, 801; (b) B. M. Trost, J. P. Stambuli, S. M. Silverman and U. Schwörer, J. Am. Chem. Soc., 2006, 128, 13328.

20 M. Fañanás-Mastral, M. Pérez, P. H. Bos, A. Rudolph, S. R. Harutyunyan and B. L. Feringa, Angew. Chem., Int. Ed., 2012, 51, 1922. 